\title{
Editorial
}

\section{Metal Phosphonates and Phosphinates}

\author{
Marco Taddei ${ }^{1, *(D)}$ and Ferdinando Costantino ${ }^{2, *(D)}$ \\ 1 Energy Safety Research Institute, College of Engineering, Swansea University, Bay Campus Fabian Way, \\ Swansea SA1 8EN, UK \\ 2 Department of Chemistry Biology and Biotechnologies, University of Perugia, Via Elce di Sotto n. 8 \\ 06127 Perugia, Italy \\ * Correspondence: marco.taddei@Swansea.ac.uk (M.T.); ferdinando.costantino@unipg.it (F.C.)
}

Received: 29 August 2019; Accepted: 29 August 2019; Published: 31 August 2019

The present Special Issue entitled "Metal phosphonates and phosphinates" aims to collect recent and significant research papers on the fascinating chemistry of these two related families of coordination compounds. Phosphonic and phosphinic acids are P-containing linkers that can be synthesized by means of several, often easily accessible, strategies, thus affording a potentially huge number of building blocks. The combination of these ligands with alkaline, main group, transition and rare-earth metals allows to prepare robust and crystalline materials to be employed in a vast number of applications, such as ion-exchange, gas sorption, molecular recognition, catalysis and as support for biomedical purposes [1]. Metal phosphonate and phosphinate chemistry has a long history, begun in the early 1970s with the pioneering work independently carried out by Prof. Abraham Clearfield (Texas A\&M University, USA) and Prof. Giulio Alberti (University of Perugia, Italy). In 1978, Alberti reported the synthesis of the first layered $\mathrm{Zr}$ phosphonate based on phenylphosphonic acid [2], whose crystal structure was then determined in 1993 by Clearfield [3]. This $\mathrm{Zr}$ derivative is considered the archetypical structure of all metal phosphonates and disclosed a new chemistry based on the rational design of synthetic materials possessing tailor-made structures and properties due to the synergistic contribution of both the metal type and organic part of the linkers. A number of dedicated reviews on this topic were published in the recent past [4-8]. However, the intensive research on new ligands of different complexity and functionality pushed this chemistry towards unexpected horizons and exciting achievements in the field of new materials discovery.

This Special Issue collects the latest contributions of several experts in the field who attended the First European Workshop on Metal Phosphonate Chemistry held in Swansea (UK) in September 2018. The workshop was a one-day event organized with the aim to open a forum of discussion for the most eminent scientists working in the field of phosphonates and phosphinates chemistry. The invited talks presented during the seminar covered a large number of topics, ranging from new synthetic strategies, porous compounds, catalysis, batteries and biomedical applications. An exhaustive overview of the workshop is collected into the collective perspective article entitled "New Directions in Metal Phosphonate and Phosphinate Chemistry" [9]. This perspective summarized all the talks given by the authors during the workshop and identified promising new avenues for research in the field. The success of the First European Workshop on Metal Phosphonate Chemistry led to the organisation of a second edition, to be held at the Federal Institute for Materials Research and Testing (BAM), in Berlin (Germany), on 24 September, 2019.

The Special Issue also presents five other contributions as original research papers. Two of these papers come from the group of Housecroft and Constable at the University of Basel and focus on phosphonate species as anchoring groups for dyes in dye-sensitized solar cells (DSCs). The one entitled "A Phosphonic Acid Anchoring Analogue of the Sensitizer P1 for p-Type Dye-Sensitized Solar Cells" [10] reports the synthesis of the first organic dye bearing a phosphonic acid anchoring 
group for p-type DSCs based on $\mathrm{FTO} / \mathrm{NiO}$ electrodes. The performance of this dye compares well with that of the benchmark analogue containing a carboxylic acid anchoring group, suggesting that phosphonic acid dyes could be successfully employed in p-type DSCs. The second article is entitled "Where Are the tpy Embraces in $\left[\mathrm{Zn}\left\{4^{\prime}-(\mathrm{EtO})_{2} \mathrm{OPC}_{6} \mathrm{H}_{4} \mathrm{tpy}_{2}\right]\left[\mathrm{CF}_{3} \mathrm{SO}_{3}\right]_{2}\right.$ ?" [11] and reports on the synthesis and structural characterization of homoleptic $\mathrm{Zn}$ complexes containing terpyridine ligands functionalised with either phosphonate or bromo groups. Structural analysis reveals that the presence of bulky diethylphosphonate pending groups introduces steric hindrance and affects the packing interactions, resulting in significant distortion of the ligand backbone, which is not observed in the bromo derivative. Another contribution to this Special Issue, entitled "Platonic Relationships in Metal Phosphonate Chemistry: Ionic Metal Phosphonates" [12] comes from the group led by Kostas Demadis at the University of Crete. In this article, a series of ionic compounds where the phosphonate species act as counteranions for positively charged metal-aquo complexes is presented. The lack of coordination between the phosphonates and the metal ions is attributed to the low nucleophilicity of oxygen atoms, due to the presence of electron-withdrawing groups that reduce the negative partial charge, as suggested by density-functional theory calculations. Finally, two articles report the synthesis of new metal phosphinates. In the paper entitled "Mechanochemical access to an elusive phosphinate-based coordination polymer" [13], Ienco and co-workers at the Italian National Research Council, University of Firenze and University of Perugia report that the water-assisted grinding of copper acetate with $\mathrm{P}, \mathrm{P}^{\prime}$-ethylene diphenylphosphinic acid affords either a 2D, open framework compound with unprecedented topology, or an anhydrous analogue with a different structural arrangement, depending on the amount of water used during the synthesis $(1 \mathrm{~mL}$ or two drops). Demel and co-workers at the Czech Academy of Sciences published a paper entitled "Novel Cerium Bisphosphinate Coordination Polymer and Unconventional Metal-Organic Framework" [14], where they report the synthesis of a pillared-layered cerium (III) coordination polymer based on the phenylene-1,4-bis(methylphosphinic acid) linker, named ICR-9, expanding the range of structures based on this linker and trivalent metals. ICR-9 is non-porous, but small changes in the synthetic procedure afford a less crystalline and defective solid, which displays porosity and can be considered as an unconventional metal-organic framework.

The contents of this Special Issue provide, also to non-specialist readers, an overview of the state-of-the-art and the recent progresses on phosphonate and phosphinate chemistry, with a focus on the synthesis of functional materials for various applications.

Conflicts of Interest: The authors declare no conflict of interest.

\section{References}

1. Clearfield, A.; Demadis, K. (Eds.) Metal Phosphonate Chemistry; Royal Society of Chemistry: Cambridge, UK, 2011; ISBN 978-1-84973-356-4.

2. Alberti, G.; Costantino, U.; Allulli, S.; Tomassini, N. Crystalline $\mathrm{Zr}\left(\mathrm{R}-\mathrm{PO}_{3}\right)_{2}$ and $\mathrm{Zr}(\mathrm{R}-\mathrm{OPO})_{2}$ compounds (R $=$ organic radical). A new class of materials having layered structure of the zirconium phosphate type. $J$. Inorg. Nucl. Chem. 1978, 40, 1113-1117. [CrossRef]

3. Poojary, M.D.; Hu, H.L.; Campbell, F.L.; Clearfield, A. Determination of crystal structures from limited powder data sets: Crystal structure of zirconium phenylphosphonate. Acta Crystallogr. Sect. B 1993, 49, 996-1001. [CrossRef]

4. Zhu, Y.P.; Ma, T.Y.; Liu, Y.L.; Ren, T.Z.; Yuan, Z.Y. Metal phosphonate hybrid materials: From densely layered to hierarchically nanoporous structures. Inorg. Chem. Front. 2014, 1, 360-383. [CrossRef]

5. Bao, S.S.; Zheng, L.M. Magnetic materials based on 3D metal phosphonates. Coord. Chem. Rev. 2016, 319, 63-85. [CrossRef]

6. Yücesan, G.; Zorlu, Y.; Stricker, M.; Beckmann, J. Metal-organic solids derived from arylphosphonic acids. Coord. Chem. Rev. 2018, 369, 105-122. [CrossRef]

7. Firmino, A.D.G.; Figueira, F.; Tomé, J.P.C.; Paz, F.A.A.; Rocha, J. Metal—Organic Frameworks assembled from tetraphosphonic ligands and lanthanides. Coord. Chem. Rev. 2018, 355, 133-149. [CrossRef] 
8. Bao, S.S.; Shimizu, G.K.H.; Zheng, L.M. Proton conductive metal phosphonate frameworks. Coord. Chem. Rev. 2019, 378, 577-594. [CrossRef]

9. Shearan, S.J.; Stock, N.; Emmerling, F.; Demel, J.; Wright, P.A.; Demadis, K.D.; Vassaki, M.; Costantino, F.; Vivani, R.; Sallard, S.; et al. New Directions in Metal Phosphonate and Phosphinate Chemistry. Crystals 2019, 9, 270. [CrossRef]

10. Klein, Y.M.; Marinakis, N.; Constable, E.C.; Housecroft, C.E. A Phosphonic Acid Anchoring Analogue of the Sensitizer P1 for p-Type Dye-Sensitized Solar Cells. Crystals 2018, 8, 389. [CrossRef]

11. Zare, D.; Prescimone, A.; Constable, E.C.; Housecroft, C.E. Where Are the tpy Embraces in $\left[\mathrm{Zn}\left\{4^{\prime}-(\mathrm{EtO})_{2} \mathrm{OPC}_{6} \mathrm{H}_{4} \mathrm{tpy}_{2}\right]\left[\mathrm{CF}_{3} \mathrm{SO}_{3}\right]_{2}\right.$ ? Crystals 2018, 8, 461. [CrossRef]

12. Ienco, A.; Tuci, G.; Guerri, A.; Costantino, F. Mechanochemical Access to Elusive Metal Diphosphinate Coordination Polymer. Crystals 2019, 9, 283. [CrossRef]

13. Xanthopoulos, K.; Anagnostou, Z.; Chalkiadakis, S.; Choquesillo-Lazarte, D.; Mezei, G.; Zaręba, J.K.; Zoń, J.; Demadis, K.D. Platonic Relationships in Metal Phosphonate Chemistry: Ionic Metal Phosphonates. Crystals 2019, 9, 301. [CrossRef]

14. Rohlíček, J.; Bůžek, D.; Brázda, P.; Kobera, L.; Hynek, J.; Brus, J.; Lang, K.; Demel, J. Novel Cerium Bisphosphinate Coordination Polymer and Unconventional Metal-Organic Framework. Crystals 2019, 9, 303. [CrossRef]

(C) 2019 by the authors. Licensee MDPI, Basel, Switzerland. This article is an open access article distributed under the terms and conditions of the Creative Commons Attribution (CC BY) license (http://creativecommons.org/licenses/by/4.0/). 